\title{
Study on the Regional Economic Differences and Its Impacts
}

\author{
Yuexin Sun ${ }^{1}$ \\ ${ }^{1}$ No. 1 Jalan Taylor's 47500 Subang Jaya, Selangor Darul Ehsan Malaysia
}

Keywords: regional economic differences; impact inspect; economy growth

\begin{abstract}
Since the reform and opening-up, China's economy has achieved remarkable results. However, it must be realized that in the period of rapid economic development in China, the gap between different regions of China's economy has gradually appeared and has gradually expanded, which has seriously affected the long-term development of China's social economy and is inconsistent with the ultimate aims of the development of socialism. Therefore, it is necessary to conduct a detailed and profound analysis of regional economic growth disparities and their influencing factors in China, so as to propose specific solutions so that regional economic disparities can be alleviated to some extent.
\end{abstract}

\section{Introduction}

In recent years, China's economy and society have grown to a greater degree and developed. The industrial structure has been continuously adjusted, the regional economic coordination has been continuously enhanced, and the overall economic quality has also been greatly improved. However, it should be noted that the current regional economy in China still has a large difference in growth. Capital, labor factors, technical factors, institutional factors, etc., to a certain extent, have made China's regional economic growth differential. Big. Specifically speaking, the differences in regional economic growth in China are mainly reflected in the difference in the gross domestic product, the difference in the growth rate of GDP, and the difference in per capita GDP. In terms of GDP, the total GDP of the eastern region accounts for more than half of the total amount of the country, and this proportion has also been rising in recent years. The gap between the eastern and central and western regions in terms of GDP is increasing. Big. In addition, the growth rate of gross domestic product also has large differences between different regions. With the implementation of the strategy for the development of the western region, the central and western regions have achieved a certain degree of economic growth, but overall their economic growth has lagged behind that of the eastern region.

\section{Analysis of Influencing Factors of Regional Economic Growth Differences}

There are many factors that cause differences in regional economic growth. There are both large-scale environmental factors outside the region and self-influence factors within the region. These factors influence and interact with each other, and together cause regional economic growth differences. Specifically, the factors that contribute to regional economic growth are capital, labor, technology, and institutional factors. These factors influence the economic growth of their own management content [1].

As an important factor influencing regional economic growth differences, the capital factor itself has a relatively broad content and concept. In a broad sense, the capital element can include related elements such as human capital, material capital, and land. Most of the studies have been simplified, considering only the capital element of physical capital input to influence regional economic growth differences. Substantial capital investment can be further divided into two kinds: liquid capital and fixed capital. In actual research and discussion, the total amount of capital formation is usually used to measure this. The total amount of capital formation can be obtained by accumulating the increase in inventory and the total amount of fixed capital formation. It is the sum of the value-added of fixed assets that can be obtained in a certain period and the change in inventory [2]. 
As an important driving force for contemporary economic and social development, technological factors have a central role in promoting the adjustment of China's economic structure and industrial upgrading, and in achieving the transformation of economic growth patterns. Focusing on the study of the differences in regional economic growth, combining the characteristics of technical elements, and tapping the characteristics of the availability of technological factors and the extensiveness of their contents, we can select input factors for technical factors, aggregate basic conditions, and output conditions for indicators. select. The first is the selection of scientific and technological activities to participate in personnel indicators. This indicator mainly refers to those who are engaged in scientific research activities and have a junior or above professional title or bachelor degree or above. It includes both personnel who directly conduct scientific research activities and those who provide support and auxiliary work for related scientific research activities. The second is the research expenditure of the whole society. This is mainly the statistical calculation of the amount of expenditures paid in support of scientific research fees in a particular region. Including labor costs, equipment and equipment purchase fees, land use fees, but also the construction of scientific research buildings, project commissioned business fees. The third is the number of patents authorized or published. This indicator mainly measures the number of patents or inventions authorized by the State Intellectual Property Office [3].

At present, the competitiveness among countries is the competition between human resources and science and technology. Science and technology have a crucial influence on economic development. For example, Silicon Valley in the United States, Bangalore in India, Zhongguancun in Beijing, China, and the surge in technology in recent years. In Hangzhou, these regions have more advanced science and technology, and thus occupy an advanced position in economic development. Science and technology mainly affect China's regional economic growth through the following aspects. The first is the strength of researchers, such as the eastern universities and research institutes in China in recent years. The Institute has dug talents from the Midwest, and some cities in the eastern part have begun to provide policies and economic support and preferential treatment for highly educated and urgently needed talents. These measures are conducive to enhancing their scientific research base and further promoting their economic growth rate; followed by social R\&D expenditures. In recent years, high-tech brands such as Huawei and Dajiang have increased investment in $\mathrm{R} \& \mathrm{D}$, which has led to greater economic benefits. These enterprises have concentrated in the eastern region, thus widening regional differences [4].

Generally speaking, in the period of underdeveloped society and economy, mainly relying on physical capital, human capital plays a decisive role when the economic development reaches a certain level. From the perspective of fixed asset investment, China's three major regions are all in an upward trend. However, in terms of total amount, the eastern region is far higher than the central and western regions. From the perspective of human capital, the imbalance in human resources between regions affects regional economic development in China. The important reason for the difference in growth, the eastern region has a certain advantage in terms of human capital.

\section{Analysis of Regional Economic Growth Differences}

In general, all regions rely mainly on the input of capital elements in the market for economic growth. In particular, analysis of the factors of market economic growth in the eastern and western regions of our country reveals that capital investment is the most important among many growth drivers. According to the content, in most regions, the economic growth is promoted and promoted by means of significant input of capital elements. At the same time, various regions have also made corresponding improvements and improvements in the quality of economic growth. This has an important positive effect in stimulating the overall economic vitality of our country, improving the quality of economic development, and tapping the potential of economic development. On this basis, the level of economic development in various regions has also developed to varying degrees. Although the factors for growth in economic development vary from region to region, capital investment is the most important factor, and the contribution of this factor Is the largest. At the same time, on the basis of the contribution of the capital input factors, the contribution of institutional 
factors and technological factors is constantly increasing and increasing. These new conditions and changes all indicate to a certain extent that the quality of economic growth in all regions has been greatly enhanced, and economic growth has taken a new leap in quality [5].

In addition to the different levels of economic growth in different regions, there is also a significant difference in economic growth between the eastern and central and western regions of China. The economic disparity between the regions also shows an ever-expanding trend. In terms of capital alone, the eastern region occupies a relatively large proportion. This has also become the most important driving factor for economic growth in the eastern region and is the most important factor leading to the difference in economic growth between the eastern region and the central and western regions. In addition to the capital factor, the labor factor also has a large gap between the eastern and western regions. Based on China's current labor-intensive and capital-intensive industrial development pattern, labor factors in the eastern region are also important for economic growth in the region. driving force. Furthermore, technological factors are also the most important influencing factors. The eastern region has great advantages in this factor, and the eastern region has gathered more and more technologies depending on its favorable geographic location and good development foundation. The accumulation of factors and technological factors is becoming an important factor in the difference in economic growth between the eastern and western regions. It is precisely because of the important role of technological factors in economic growth. Both the eastern and western regions have paid increasing attention to this key factor in economic development.

\section{Countermeasures to Reduce the Differences in Regional Economic Growth in China}

The nature of our country as a socialist country determines that we must achieve common prosperity and cannot achieve polarization. Therefore, we must actively accelerate regional coordinated development, mainly from the following aspects: First, to attract investment, from the national level to the economically underdeveloped regions in the central and western regions. With regard to preferential policies, the local government must also formulate policies that are conducive to attracting investment and promote economic development. The second is to eradicate the poverty-stricken population. Under the leadership of the Party Central Committee in recent years, all regions in China have begun to implement accurate poverty alleviation. Through support and assistance to the poor, people have been guaranteed basic lives. The third is to attract college graduates to return to build their hometowns. As mentioned above, the importance of human resource factors for regional economic development has already been mentioned. Therefore, the regional government must attach great importance to the introduction of talents, provide life guarantee for the shortage of talents, and resolve their worries; It is necessary to encourage young people to start their own businesses and to attract local entrepreneurs outside China to attract their hometown businesses through preferential policies and promote hometown economic development. In view of the current regional economic growth in China, we must put forward effective measures to improve this situation. First, the regions that attract investment and the economic development is relatively backward need to actively attract foreign investment. Foreign investment has a direct impact on economic growth. Local governments in the region need to formulate policies that are conducive to attracting investment and give certain preferential measures to investment projects so as to promote economic development. The second is to improve basic living security. In regions with slow economic development, the situation of population loss is prone to occur. Most people will go to regions with rapid economic development, leading to this situation, mainly because people's basic lives are not guaranteed. Therefore, the local government must carry out effective measures to increase people's corresponding subsidies and subsidies so that people's basic lives can be guaranteed. The third is to encourage young people to start businesses. For the economically backward regions, while actively introducing foreign investors, it is also necessary to give full play to the advantages of the region. Local governments need to confiscate the lost young people, encourage them to return to their hometowns for entrepreneurship, and promote hometown economic development. The government needs to formulate corresponding loan policies and 
provide financial support and other preferential measures for entrepreneurial activities so as to solve the shortage of funds faced by young people. The fourth is to attract college graduates to return to their hometowns. Many college graduates are not only technical but also powerful, and are very valuable resources. Therefore, the economically backward regional government must pay more attention to graduates, provide basic living guarantees for graduates, or solve problems such as preparation, so as to solve the worries of graduates.

\section{Conclusion}

China's social development must closely follow the basic idea of taking economic construction as the center. Despite the differences in regional economic growth at the stage of economic development, it is also necessary for the Chinese government and people to face each other. Strengthen scientific and in-depth analysis of influencing factors, fully recognize the regional economic differences between the eastern and western regions of China, and propose concrete solutions to prevent the widening of differences; economically backward regions also need to continue to develop appropriate countermeasures to promote the sustainable development of the local economy. Development gradually reduces the difference in economic development.

\section{References}

[1] Wu Jun, Wei Anxi. Analysis of the Trend Decomposition of Spatial Correlation of Regional Economy and Its Influencing Factors--Concurrent Policy Suggestions of "One Belt and One Road" Strategy [J]. Economic Survey, Economic Survey, Longitude, 2018, (01): 1-10.

[2] Wang Xinya. On the differences of regional economic growth in China and its influencing factors [J]. Finance and Economics (Academic Edition), 2016, (13): 21.

[3] Zhang Yi. An analysis of the differences in county economy in China[J]. Chinese Rural Economy, 2012(11)

[4] Pan Wenqing. Regional economic differences and convergence in China [J]. Chinese Social Sciences, 2013 (1)

[5] Li Caixia. Analysis of Regional Economic Growth Differences and Influencing Factors in China [J]. Oriental Corporate Culture, 2015, (14): 136 